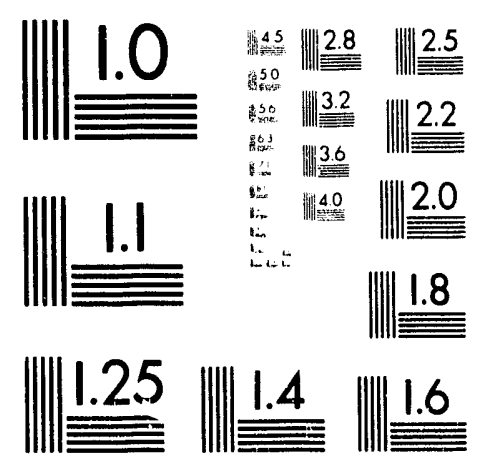



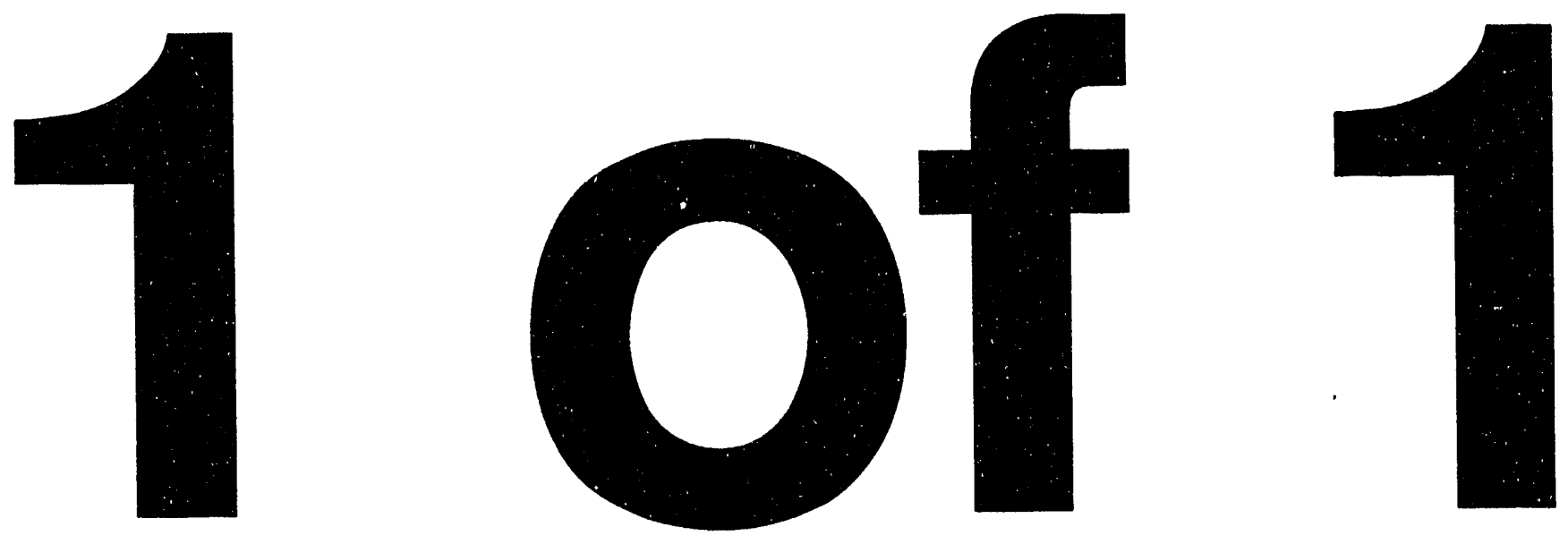


\section{Argonne National Laboratory \\ 9700 South Cass Avenue \\ Argonne, Illinois 60439}

\section{FREE VIBRATION ANALYSIS OF PARTIALLY FILLED LIQUID STORAGE TANKS}

by

Yu Tang and Y. W'. Chang

Reactor Engineering Division

May 1993
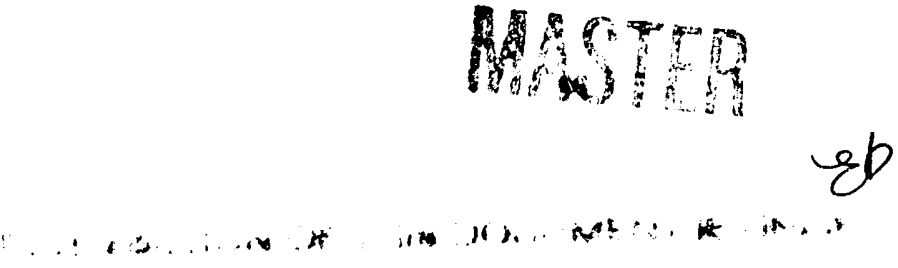

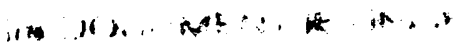


ABSTRACT $\ldots \ldots \ldots \ldots \ldots \ldots \ldots \ldots \ldots \ldots \ldots \ldots \ldots \ldots \ldots \ldots \ldots \ldots \ldots$

I. INTRODUCTION $\ldots \ldots \ldots \ldots \ldots \ldots \ldots \ldots \ldots \ldots \ldots \ldots \ldots \ldots$

II. SYSTEM DESCRIPTION $\ldots \ldots \ldots \ldots \ldots \ldots \ldots \ldots \ldots \ldots \ldots \ldots \ldots \ldots \ldots$

III. METHOD OF ANALYSIS $\ldots \ldots \ldots \ldots \ldots \ldots \ldots \ldots \ldots \ldots \ldots \ldots$

A. Kinetic Energy of Tank, $T_{s} \ldots \ldots \ldots \ldots \ldots \ldots \ldots \ldots \ldots$

B. Strain Energy of Tank, $S \ldots \ldots \ldots \ldots \ldots \ldots \ldots \ldots \ldots$

C. The Governing Equations and Boundary Conditions fo Liquid Field . . 6

D. Kinetic Energy of Liquid, $T_{1} \ldots \ldots \ldots \ldots \ldots \ldots \ldots \ldots$

E. Eigenvalue Problem $\ldots \ldots \ldots \ldots \ldots \ldots \ldots \ldots \ldots \ldots \ldots$

IV. NUMERICAL RESULTS $\ldots \ldots \ldots \ldots \ldots \ldots \ldots \ldots \ldots \ldots \ldots \ldots \ldots \ldots$

A. Fundamental Natural Frequency $\ldots \ldots \ldots \ldots \ldots \ldots \ldots \ldots, 10$

B. Fundamental Mode of Hydrodynamic Pressure $\ldots \ldots \ldots \ldots \ldots \ldots$

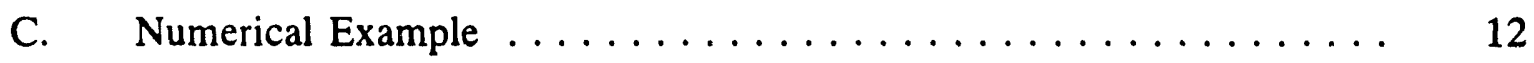

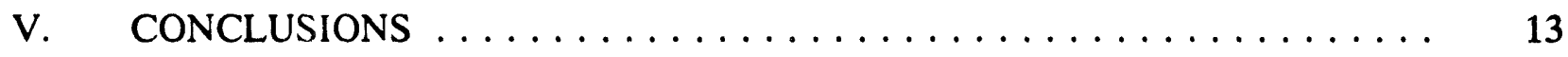

ACKNOWLEDGMENT $\ldots \ldots \ldots \ldots \ldots \ldots \ldots \ldots \ldots \ldots \ldots \ldots \ldots \ldots$

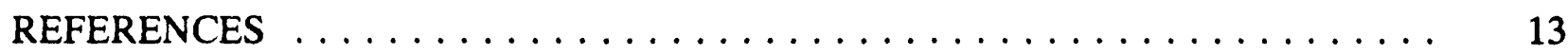




\section{LIST OF TABLES}

Page

I Convergence Table of Frequency Coefficient, $C_{1} \ldots \ldots \ldots \ldots \ldots$

II Fundamental Natural Frequency for Steel Tanks with Top Free Boundary

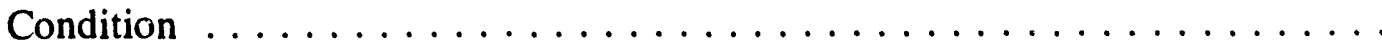

III Fundamental Natural Frequency for Steel Tanks with Top Hinged

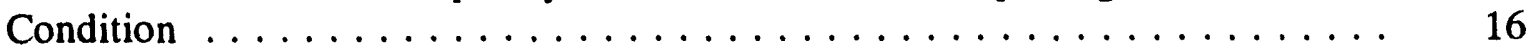

IV Fundamental Natural Frequency for Steel Tanks with Top Roller Condition . . 16

V Frequency Coefficient, $C_{1}$, for Partially Filled Tanks with Top Free

Boundary Condition ......................... 17

VI Frequency Coefficient, $C_{1}$, for Partially Filled Tanks with Top Hinged

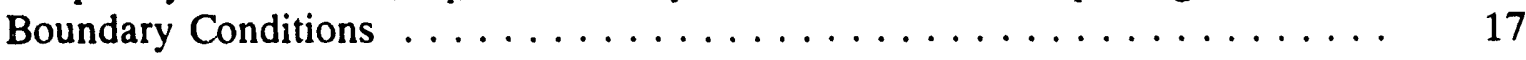

VII Frequency Coefficient, $\mathrm{C}_{1}$, for Partially Filled Tanks with Top Roller

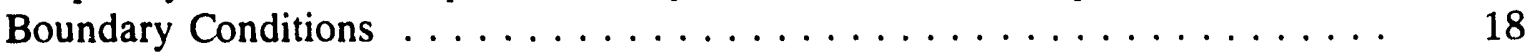

VIII Frequency Coefficient, $C_{1}$, for Partially Filled Tanks with Top Free Boundary Condition ......................... 18

IX Frequency Coefficient, $C_{1}$, for Partially Filled Tanks with Top Hinged Boundary Conditions .............................. 19

$\mathrm{X}$ Frequency Coefficient, $\mathrm{C}_{1}$, for Partially Filled Tanks with Top Roller

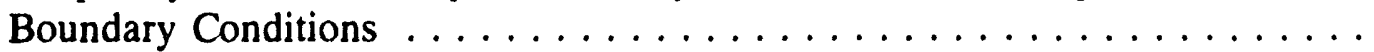

XI Natural Frequencies of Partially Filled Tanks in the Numerical Example,

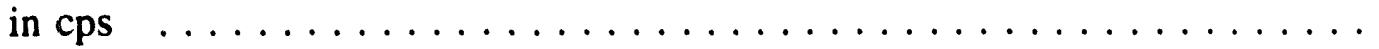




\section{LIST OF FIGURES}

No.

Title

$\underline{\text { Page }}$

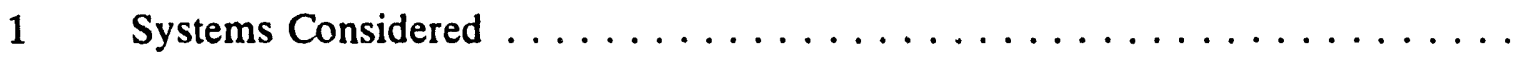

2 Fundamental Modal Pressure Exerted on Tank Wall with Top Free

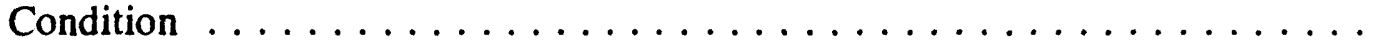

3 Fundamental Modal Pressure Exerted on the Tank Wall with Top Hinged

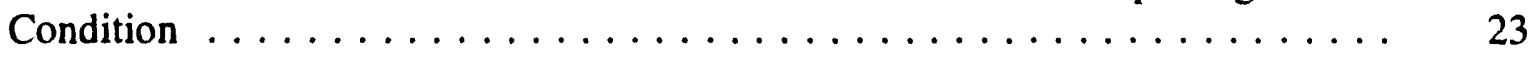

$4 \quad$ Fundamental Modal Pressure Exerted on Tank Wall with Top Roller

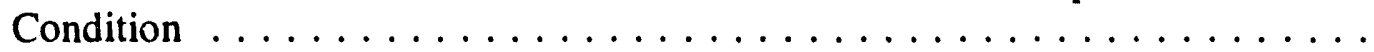




\title{
FREE VIBRATION ANALYSIS OF PARTIALLY \\ FILLED LIQUID STORAGE TANKS
}

\author{
by
}

Yu Tang and Y. W. Chang

\begin{abstract}
A study on the free vibration analysis of partially filled liquid storage tanks is presented. The tanks considered are the upright circular cylindrical tanks that are rigidly supported at the base. The top of the tanks are either free or constrained. Two types of constraints are considered, namely, hinged and roller support. The governing differential equations for the tank-liquid system are obtained by application of the Rayleigh-Ritz procedure in combination with Lagrange's equation. The response functions examined include the frequency of the fundamental mode of vibration of the tank-liquid system and the associated modal pressure.
\end{abstract}




\section{INTRODUCTION}

The dynamic response of liquid-storage tanks subjected to earthquake ground motion has been a subject of numerous studies in the past thirty years. An review on this subject can be found in Ref. 1. Most of the previous studies were based on the assumptions that the tank is fixed at its base and free at its top, and the tank is fully filled with liquid. However, a large number of high level waste storage tanks at various Department of Energy (DOE) facilities are constrained at top. The dynamic behavior of these top constrained tanks are believed to be quite different from those of the cantilever tanks. In order to understand the dynamic responses of these top constrained tanks, the dynamic characteristics of these tanks need to be examined. Also, to assess the adequacy of the assumption that a partially filled tank can be considered as fully filled with liquid, the dynamic characteristics of a partially filled tank is studied. Thus, the objectives of this report are: (1) to understand the effect of the constraints at the top of a tank on the dynamic characteristics of the liquid storage tanks; and (2) to assess the adequacy of the assumption that treats a partially filled tank to be a fully filled tanks.

The method of analysis presented herein is similar to that used in Arya, Thakkar and Goyal [2], and is basically the same as that used by Tang [3] and Yang [4], except that different functions are used herein in the expansion of shell displacements, and that the tank is considered to be partially filled if the liquid level is not at the top of the tank. This approach is based $\mathrm{cn}$ the Rayleigh-Ritz energy procedure in which the deflections of the tank wall are assumed to be linear combinations of the admissible functions. The governing differential equations of the tankliquid system are obtained by the application of Lagrange's equation.

Like the previous studies of Housner [5] and Veletsos [1], the hydrodynamic pressure is divided into two components: the impulsive component and the convective component. For the definitions of these two components, the reader is referred to Refs. 1 and 5. It has been pointed out by Veletsos [1] and Veletsos and Yang [6] and confirmed by Housner and Haroun [7,8] that the effect of the tank flexibility on the convective component is unimportant and can be neglected. Therefore, only the impulsive component is examined in this report. Note that the convective component can be evaluated by considering the tank to be rigid. 


\section{SYSTEM DESCRIPTION}

The tank-liquid systems investigated are shown in Fig. 1. The tank is a ground-supported upright circular cylindrical shell with uniform wall thickness $h$, radius $R$, and height $L$. The tank is filled with liquid to a height of $\mathrm{H}$. The density of the liquid is denoted by $\rho_{\mathrm{r}}$. The density and Young's modulus of the shell material are denoted by $\rho$ and $E$, respectively. The liquid storage tanks shown in Fig. 1 have three different constraints at the top but they all are assumed to be fixed at the base. The tank shown in Fig. 1a is free at the top, in Fig. 1b is hinged at the top and in Fig. 1c is roller-supported at the top. The difference between the system of Fig. 1b and that of Fig. 1c is that the roller support can move freely in the axial direction whereas the hinge support is restrained in the axial direction movement. The cylindrical coordinate system is used herein in which a point of the tank-liquid system is defined by the coordinates, $r, \theta$, and z. The displacements in the direction of the coordinates are denoted by $w, v$ and $u$, respectively. The liquid is assumed to be incompressible and nonviscous.

\section{METHOD OF ANALYSIS}

The analysis is carried out by the application of the Rayleigh-Ritz method in combination with Lagrange's equation to obtain the governing differential equations.

The axial, tangential and radial components of the deflections of a point on the tank wall, $u, v$ and $w$ respectively, are expressed in terms of generalized coordinate functions $\chi_{i}(z)$ and $\psi_{i}(z)$, i.e.,

$$
\begin{aligned}
& u=\sum_{i=1}^{N 1} U_{i}(t) \chi_{i}(z) \cos \theta \\
& v=\sum_{i=1}^{N 2} V_{i}(t) \psi_{i}(z) \sin \theta \\
& w=\sum_{i=1}^{N 3} W_{i}(t) \psi_{i}(z) \cos \theta
\end{aligned}
$$

where $U_{i}(t), V_{i}(t)$ and $W_{i}(t)$ are time-dependent displacement amplitudes of the ith coordinate functions $\chi_{i}(z)$ and $\psi_{i}(z)$, and N1, N2 and N3 are the number of coordinate functions used to 
approximate the displacements. The generalized functions $\chi(z)$ and $\psi(z)$ used herein for the three systems shown in Fig. 1 are given as follows.

(a) System shown in Fig. 1a

$\chi_{i}(z)=$ the first derivative of $\psi_{i}(z)$

$\psi_{i}(z)=$ the ith natural mode of flexural vibration of a uniform cantilever beam

(b) System shown in Fig. 1b

$\chi_{i}(z)=$ the ith natural mode of extensional vibration of a uniform beam clamped at both ends.

$\psi_{i}(z)=$ the ith natural mode of flexural vibration of a uniform beam clamped at $z=0$ and free at $z=L$.

(c) System shown in Fig. 1c

$\chi_{i}(z)=$ the ith natural mode of extensional vibration of a uniform beam clamped at $z=0$ and simply supported at $z=L$.

$\psi_{i}(z)=$ the ith natural mode of flexural vibration of a uniform beam clamped at $z=0$ and simply supported at $z=L$.

The expressions for the above mentioned functions for $\chi_{i}(z)$ and $\psi_{i}(z)$ can be found in most structural dynamic text books, e.g., Paz [9]. Note that these generalized functions are geometrically admissible since they satisfy the geometric boundary conditions of the system considered.

The governing differential equations are obtained by the application of Lagrange's equation given as

$$
\frac{d}{d t}\left(\frac{\partial\left(T_{s}+T_{l}\right)}{\partial \dot{q}_{i}}\right)-\frac{\partial\left(T_{s}+T_{1}\right)}{\partial q_{i}}+\frac{\partial S}{\partial q_{i}}=0
$$

for the ith equation in which $T_{s}$ is the kinetic energy of the tank and $T_{l}$ is the kinetic energy of 
the liquid; $S$ is the strain energy of the tank wall, and $q_{i}$ is the generalized coordinates. In this study $q_{i}=U_{i}$ or $V_{i}$ or $W_{i}$. Obviously, if $T_{i}=0$, one would obtain the governing differential equations for the empty tank.

A. Kinetic Energy of Tank, $\mathbf{T}$.

The kinetic energy of the tank is given by

$$
T_{8}=\frac{\rho h}{2} \int_{0}^{2 \pi} \int_{0}^{L}\left(\dot{u}^{2}+\dot{v}^{2}+\dot{w}^{2}\right) R d z d \theta
$$

in which a dot superscript denotes the differentiation with respect to time.

\section{B. Strain Energy of Tank, $S$}

The strain energy of the tank is computed by making use the expression given in Bleich and Dimaggio [10]. It is

$$
\begin{aligned}
S & =\frac{E}{2\left(1-v^{2}\right)} \frac{h}{R} \int_{0}^{2 \pi} \int_{0}^{L}\left[R^{2} u_{z}^{2}+\left(v_{\theta}+w\right)^{2}\right. \\
& \left.+2 v R u_{z}\left(v_{\theta}+w\right)+\frac{1-v}{2}\left(u_{\theta}+R v_{z}\right)^{2}\right] d z d \theta \\
& +\frac{E}{24\left(1-v^{2}\right)} \frac{h^{3}}{R^{3}} \int_{0}^{2 \pi} \int_{0}^{H}\left[R^{4} w_{z z}^{2}+\left(w_{\theta \theta}+w\right)^{2}\right. \\
& +\frac{1-v}{2}\left(R w_{z \theta}-u_{\theta}\right)^{2}+\frac{3(1-v)}{2} R^{2}\left(v_{z}+w_{z \theta}\right)^{2}
\end{aligned}
$$




$$
\left.+2 v R^{2} w_{z z}\left(w_{\theta \theta}-v_{\theta}\right)-2 R^{3} u_{z} w_{z z}\right] d z d \theta
$$

in which the terms in the first bracket represent the extensional energy and the terms in the second bracket represent the bending energy. The subscripts $z$ and $\theta$ in the expression represent the derivatives of the quantity considered with respect to $z$ and $\theta$. Note that the expression presented in Eq. (7) differs a sign for $w$ from that given in Bleich and Dimaggio [10]. This is due to the different sign convention used for $w$ in this report.

Substituting the expressions for $T_{8}$ and $S$ into Eq. (5), omitting $T_{1}$ from the equation, and after repeating application of Eq. (5), one obtains a set of governing equations for the free vibration analysis of empty tanks. This can be found in Ref. 4 where the resultant equations are presented in a matrix form given by

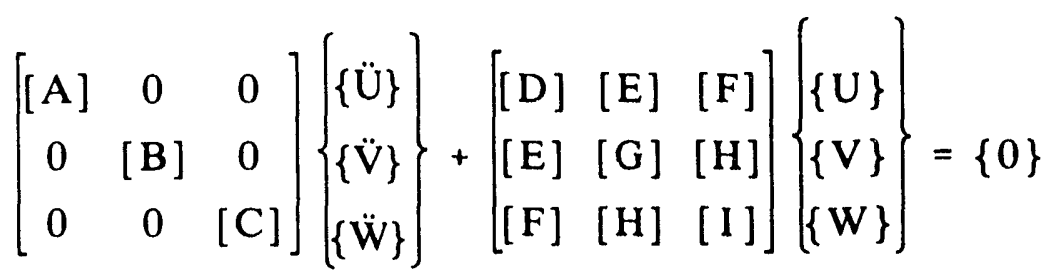

where $[A]$ through $[1]$ are square submatrices, and $\{U\},\{V\}$ and $\{W\}$ are the column submatrices whose elements are $U_{i}, i=1,2, \ldots, N 1 ; V_{i}, i=1,2, \ldots, N 2$; and $W_{i}, i=1,2, \ldots, N 3$, respectively. The elements of matrices [A] through [I] and the details of derivation of Eq. (8) can be found in Ref. 4. For the sake of presentation, Eq. (8) is written in a more compact form as

$$
[M]\{\ddot{q}\}+[K]\{q\}=\{0\}
$$

with the column matrix $\{q\}$ defined by

$$
\{q\}=\left\{U_{1}(t), U_{2}(t), \ldots, U_{N 1}(t), V_{1}(t), V_{2}(t), \ldots, V_{N 2}(t),\right.
$$




$$
\left.\mathrm{W}_{1}(\mathrm{t}), \mathrm{W}_{2}(\mathrm{t}), \ldots, \mathrm{W}_{\mathrm{N}_{3}}(\mathrm{t})\right\}^{\mathrm{T}}
$$

where the superscript $T$ denotes the transpose of the row matrix.

It has been shown in Ref. 4 that the governing equations for a tank filled with liquid can be obtained by including the so-called liquid added mass to the mass matrix of the empty tank, and this liquid added mass is added to the elements associated with the radial displacement only; the presence of the liquid has no effect on the stiffness matrix, $[K]$. Specifically, if $c_{i j}$ denotes the element of the submatrix [C] in Eq. (8), $c_{i j}$ needs to be replaced by $c_{i j}{ }^{*}$ where $c_{i j}^{*}$ is related to $c_{i j}$ by

$$
c_{i j}^{*}=c_{i j}+m_{i j}^{\prime}
$$

The quantity $\mathrm{m}_{\mathrm{ij}}^{\prime}$ in Eq. (11) is the so-called liquid added mass. The same procedure is employed herein to obtain the governing equations for partially filled tank-liquid systems considered herein. The equation for computing the corresponding liquid added mass is presented as follows.

\section{The Governing Equations and Boundary Conditions for Liquid Field}

Given the conditions that the liquid is incompressible and inviscid, the velocity potential for liquid, denoted by $\phi$, must satisfy the Laplace equation

$$
\nabla^{2} \phi=0
$$

in the region $0 \leq r \leq R, 0 \leq \theta \leq 2 \pi$, and $0 \leq z \leq H$.

The liquid velocity at an arbitrary point along $x$-direction, $v_{x}$, is related to $\phi$ by the equation

$$
v_{x}=-\frac{\partial \phi}{\partial x}
$$


The boundary conditions for the liquid field are:

(a) The vertical velocity of the liquid at the tank base must equal zero, i.e.,

$$
\left.\frac{\partial \phi}{\partial z}\right|_{z=0}=0
$$

(b) The radial velocity of the liquid adjacent to the tank wall must equal the velocity of the tank wall, i.e.,

$$
-\left.\frac{\partial \phi}{\partial v}\right|_{r=R}=\dot{w}=\sum_{i=1}^{N 3} \dot{W}_{i}(t) \psi_{i}(z) \cos \theta
$$

(c) At the free surface, the pressure is equal to zero, i.e.,

$$
\left.\frac{\partial \phi}{\partial \mathrm{t}}\right|_{\mathbf{z}=\mathrm{H}}=0
$$

and the value of $d$ at $r=0$ is finite.

The method of separation of variables is used to solve the differential equation (12). Satisfying the boundary conditions, Eqs. (14) and (16), the function $\phi(r, \theta, z, t)$ takes the form

$$
\phi(r, \theta, z, t)=\sum_{n=1}^{\infty} C_{n}(t) I_{1}\left[\alpha_{n} \frac{r}{H}\right] \cos \left[\alpha_{n} \frac{z}{H}\right] \cos \theta
$$

in which $I_{1}$ is the modified Bessel function of the first kind, $C_{n}(t)$ is a time-dependent function that may be determined from Eq. (15), and $\alpha_{n}=(2 n-1) \pi / 2$. After $C_{n}(t)$ is determined from Eq. (15), and the resultant is substituted into Eq. (17), one obtains 


$$
\phi=-\sum_{i=1}^{N 3} \dot{w}_{1}(t) \sum_{n=1}^{\infty} \frac{2 H}{\alpha_{n}} \frac{I_{1}\left[\alpha_{n} \frac{r}{H}\right]}{I_{1}^{\prime}\left[\alpha_{n} \frac{R}{H}\right]} d_{i n} \cos \left(\alpha_{n} \frac{z}{H}\right)
$$

in which

$$
\alpha_{i n}=\frac{1}{H} \int_{0}^{H} \psi_{i}(z) \cos \left(\alpha_{n} \frac{z}{H}\right) d\left(\frac{z}{H}\right)
$$

\section{Kinetic Energy of Liquid, $T$,}

For the incompressible nonviscous fluid, it has been shown by Currie [11] that the kinetic energy of the liquid can be evaluated by the equation

$$
T_{l}=\frac{\rho_{l}}{2} \int_{l} \int \phi \frac{\partial \phi}{\partial n} d s
$$

in which $\phi$ is the velocity potential function and $\partial \phi / \partial n$ is the derivative of $\phi$ in the direction normal to the boundary of the fluid. The symbol $s$ in Eq. (20) represents a surface integral, and the integration covers the wet surface of the liquid field. The only non-zero part of the surface integral in Eq. (20) is the one associated with the tank wall. The value of $\partial \phi / \partial \mathrm{n}$ in this case is equal to $\partial \phi / \partial r$. The part corresponding to the tank bottom is zero because the vertical velocity is zero, and the part corresponding to the free surface is zero because the pressure is assumed to be zero. After eliminating those zero surface integrals, Eq. (20) can be rewritten as

$$
T_{1}=\frac{\rho_{l}}{2} \int_{0}^{2 \pi} \int_{0}^{H}\left[\phi \frac{\partial \phi}{\partial r}\right]_{r=R} R d z d \theta
$$


Substituting Eq. (18) into Eq. (21) and performing the required integration, the final result may be cast into the equation given by

$$
T_{1}=\frac{1}{2} \sum_{i=1}^{N 3} \sum_{j=1}^{N 3} m_{i j}^{f} \dot{w}_{i} \dot{w}_{j}
$$

where

$$
m_{i j}^{\prime}=\left[\frac{H}{R} \sum_{n=1}^{\infty} \frac{2}{\alpha_{n}} \frac{I_{1}\left(\alpha_{n} \frac{R}{H}\right)}{I_{1}^{\prime}\left(\alpha_{n} \frac{R}{H}\right)} d_{i n} d_{j n}\right] m_{1}
$$

in which $m_{1}=\pi \rho_{l} R^{2} H=$ total liquid mass. Equation (23) is the liquid added mass mentioned in Eq. (11).

\section{E. Eigenvalue Problem}

Replacing elements $c_{i j}$ by $c_{i j}^{*}$ in the mass matrix, $[M]$, and assuming that the time function of the vibration is a sinusoidal function, Eq. (9) leads to the standard form of an eigenvalue problem

$$
[k]\{q\}=\omega^{2}[M]\{q\}
$$

where $\{q\}=$ the eigenvector which is the vector of the displacement amplitudes of vibration, and $\omega=$ the eigenvalue which is the natural circular frequency of the tank-liquid system. 


\section{NUMERICAL RESULTS}

Unlike the case of a fully filled tank where the response is controlled by four parameters, $H / R, h / R, \rho_{d} / \rho$, and $\nu$, the response of a partially filled tank is controlled by five parameters. They are $L / R, h / R, \rho_{/} \rho, v, H / L$.

\section{A. Fundamental Natural Frequency}

The fundamental natural frequency of the tank-liquid system may conveniently be expressed in the form of

$$
f_{i}=\frac{1}{2 \pi} \frac{C_{i}}{L} \sqrt{\frac{E}{\rho}}
$$

in which $f_{i}$ has the unit of $\mathrm{Hz}$ (cycles per second), and $C_{i}$ is a nondimensional coefficient.

Values of $C_{1}$ for steel tanks $\left(\rho_{\mathrm{f}} / \rho=0.127, h / R=0.001, v=0.3\right)$ with $L / R=0.5,1,2$ and 3 and $\mathrm{H} / \mathrm{L}=1$ were obtained by using different combinations of N1, N2 and N3 for top-hinged and top-roller systems, and the results are listed in Table I. As expected, the value of $\mathrm{C}_{1}$ decreases monotonously as the numbers of terms, N1, N2 and N3 increase. It is noted that in Table I, the values of N1, N2 and N3 stop increasing at N1=9, N2=9 and N3=9 and the last row of $C_{1} \mathrm{~s}$ are for the combination of $\mathrm{N} 1=10, \mathrm{~N} 2=15$ and $\mathrm{N} 3=20$. The reason is that the combination of $N 1=9, N 2=9$ and $N 3=9$ will be used in the computation of the frequencies for the partially filled tanks because in the evaluation of the integral defined in Eq. (19) for the partially filled tank, the vibration modes of a uniform beam need to be evaluated at intermediate points and end points, and it has been found that even with the double precision words of the digital computer, these vibration modes can be calculated accurately only up to the ninth mode. Therefore, to assess the accuracy of the numerical results obtained by taking $N 1=9, N 2=9$ and $N 3=9$, the results obtained by taking the combination of $\mathrm{N} 1=10, \mathrm{~N} 2=15$ and $\mathrm{N} 3=20$ are included in Table I. It has been shown by Tang [3] that the latter combination yields very accurate results for the fully filled tank-liquid system shown in Fig. 1a. Note that for the case of $H / L=1$, only the two 
end points of the vibration modes need to be calculated, and the exact values for these two end points are available in Ref. 12. From Table I one can see clearly that the difference of the results obtained by the last two combinations of N1, N2 and N3 is less than 3 percent, which is within engineering accuracy. Thus all solutions presented hereinafter are obtained by using the combination of $\mathrm{N} 1=9, \mathrm{~N} 2=9$ and $\mathrm{N} 3=9$.

To study of the effect of the control parameter, $H / L$, on the fundamental natural frequency, the values of $\mathrm{C}_{1}$ are presented in Tables II, III and IV for the three systems (a), (b) and (c) shown in Fig. 1, respectively. The tanks considered are steel tanks with $h / R=0.001$, $v=0.3$ and $\rho_{/} / \rho=0.127$; four different values of $H / L$ are considered, $H / L=1,0.8,0.6$ and 0.5 for the eight values of $L / R$ in the range of 0.3 to 3.0. As one would have expected, the values of $\mathrm{C}_{1}$ increase with the decrease of the values of $\mathrm{H} / \mathrm{L}$, which is reasonable because as the value of $\mathrm{H} / \mathrm{L}$ decreases so is the liquid added mass; as a results, the natural frequency of the tank-liquid increases.

Due to lack of information on the response of partially filled tank, it is a common practice that in the computation of the fundamental natural frequency of a partially filled tank, the tank height is assumed equal to the liquid height and the system is treated as if the tank is fully-filled. With the method of analysis presented herein, the accuracy of this approximate approach can be assessed easily. The comparisons of numerical results for the exact solution and approximate approach for the fundamental natural frequency of the three tank-liquid systems for the steel tanks, $h / R=0.001, \nu=0.3$ and $\rho / \rho=0.127$ are presented in Tables $V, V I$ and VII; the corresponding information for the concrete tanks, $h / R=0.01, v=0.15$ and $\rho / \rho=0.4$ are presented in Tables VIII, IX, and X. Examining these tables, one can see that for steel tanks the approximate approach yields quite accurate results for lower values of $L / R$, and the accuracy deteriorates with higher values of $\mathrm{L} / \mathrm{R}$. As for the concrete tanks, good accuracy is observed for the values of $L / R$ in the range between 0.5 and 1.5 ; for tall tanks, the result may be off by 17 percent.

\section{B. Fundamental Mode of Hydrodynamic Pressure}

The fundamental mode of the hydrodynamic pressure exerted at the tank wall can be 
obtained by replacing $\dot{w}$ in Eq. (18) by the values of $W_{i}$ in the first eigenvector obtained from Eq. (24); then, substituting the resultant equation in the following equation to compute the modal pressure.

$$
P=\rho_{1} \frac{\partial \phi}{\partial t}
$$

and the pressure exerted at the tank wall is obtained by evaluating Eq. (26) at $r=R$. As it can be seen, the circumferential distribution of the pressure is proportional to $\cos \theta$.

The distributions of the fundamental modal pressure exerted at the tank wall for three tank-liquid systems shown in Fig. 1 are presented in Figs. 2, 3 and 4, respectively, for $L / R=0.5$ and 3 and $H / L=1,0.75$ and 0.5 . It is shown in these figures that the pressure distribution for $L / R=0.5$ is different from that for $L / R=3$, but the shape remains the same irrespective to the value of $\mathrm{H} / \mathrm{L}$. The pressure distributions are similar to each other for three tank-liquid systems considered.

\section{Numerical Example}

The method of analysis presented herein has been implemented into a pc-based digital computer program. To validate its accuracy, a numerical example is given herein to compare the results obtained by the present method of analysis with those obtained by the FEM method which was presented in the paper by Haroun and Housner [7].

Two tanks are considered, one is identified as "Broad Tank" which has the following

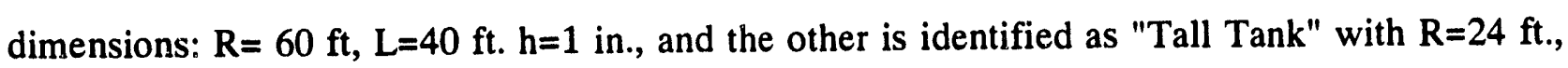
$\mathrm{L}=72 \mathrm{ft}$. and $\mathrm{h}=1 \mathrm{in}$. Both tanks are made of steel with the properties of $\mathrm{E}=30 \times 10^{6} \mathrm{psi}, v=0.3$ and $\rho=490 \mathrm{lb}$. The tank is filled with water with density of $62.4 \mathrm{lb}$./ft. The tank is free at the top. The frequencies for the first two modes of vibration are computed, and the results are listed in Table XI along with those presented in the paper by Haroun and Housner [7]. One can see that the results obtained by two methods are in good agreement. 


\section{CONCLUSIONS}

An analytical method of analysis for the study of the dynamic characteristics of partially filled tanks is presented. The method is based on the Rayleigh-Ritz procedure in combination with Lagrange's equation. The liquid region is solved analytically, and the displacements of the tank wall are expanded by the vibration modes of the uniform beam. The method is easy to implement and may be expanded to include seismic excitations. The study shows that unlike the case of fully-filled tank-liquid system in which the response is controlled by four parameters, the partially-filled tank is controlled by five parameters. The approximate approach that assumes tank height equal to the liquid height in the computation of the response of partially-filled tanks yields fairly accurate results for the value of $L / R$ in the range of 0.5 to 1.5 .

\section{ACKNOWLEDGMENT}

The authors wish to thank Mr. Ralph Seidensticker of Argonne National Laboratory for helpful discussions during the performance of this work. This work was performed in the Engineering Mechanics Program of the Reactor Engineering Division of Argonne National Laboratory under the auspices of the U.S. Department of Energy, Contract No. W-31-109-Eng-38.

\section{REFERENCES}

1. A. S. Veletsos, "Seismic Response and Design of Liquid Storage Tanks," Guidelines for the Seismic Design of Oil and Gas Pipeline Systems, Technical Council on Lifeline Earthquake Engineering, ASCE, pp. 255-370 and 443-461 (1984).

2. A. S. Arya, S. K. Thakkar, and A. C. Goyal, "Vibration Analysis of Thin Cylindrical Containers," J. Engrg. Mechanics, ASCE, Vol. 97, No. 2, pp. 317-331 (1971).

3. Y. Tang, "Studies of Dynamic Response of Liquid Storage Tanks," thesis presented to Rice University, Houston, TX, in partial fulfillment of the requirements for the degree of Doctor of Philosophy (1986).

4. J. Y. Yang, "Dynamic Behavior of Fluid-Tank Systems," thesis presented to Rice University, Houston, TX, in partial fulfillment of the requirements for the degree of Doctor of Philosophy (1976).

5. G. W. Housner, "Dynamic Pressure on Accelerated Fluid Container," Bull. Seismological Soc. of America, Vo. 47, pp. 15-35 (1957). 
6. A. S. Veletsos and J. Y. Yang, "Earthquake Response of Liquid Storage Tanks," Advances in Civil Engineering Through Engineering Mechanics, Proceedings of the Engineering Mechanics Division Specialty Conference, ASCE, Rayleigh, NC, pp. 1-24 (1977).

7. M. A. Haroun and G. W. Housner, "Dynamic Characteristics of Liquid Storage Tanks," J. Engrg. Mechanics, ASCE, Vol. 108, No. 5, pp. 783-800 (1982).

8. M. A. Haroun and G. W. Housner, "Complications in Free Vibration Analysis of Tanks," J. Engrg. Mechanics, ASCE, Vol. 108, No. 5, pp. 801-818 (1982).

9. M. Paz, Structural Dynamics, Van Nostrand Reinhold Co., New York, NY (1985).

10. H. H. Bleigh and F. Dimaggio, "A Strain-Energy Expression for Thin Cylindrical Shells," J. of Applied Mechanics, ASME, Vol. 75, pp. 448-449 (1953).

11. I. G. Currie, Fundamental Mechanics of Fluids, McGraw-Hill Book Company, New York, NY (1974).

12. R. P. Felgar, "Formulars for Integrals Containing Characteristics Functions of Vibrating Beams," Texas University, Bureau of Engineering Resea ch, Circular No. 14 (1950). 
Table I. Convergence Table of Frequency Coefficient, $\mathrm{C}_{1}$, (steel tanks with $h / R=0.001, \rho_{d} / \rho=0.127, v=0.3$ )

\begin{tabular}{|c|c|c|c|c|}
\hline \multirow[b]{2}{*}{$\begin{array}{c}\text { No. of } \\
\text { Terms } \\
\text { N1-N2-N3 }\end{array}$} & \multicolumn{4}{|c|}{ Frequency Coefficient, $C_{1}$} \\
\hline & $\mathrm{H} / \mathrm{R}=0.5$ & $\mathrm{H} / \mathrm{R}=1$ & $\mathrm{H} / \mathrm{R}=2$ & $\mathrm{H} / \mathrm{R}=3$ \\
\hline & \multicolumn{4}{|c|}{ (top hinged) } \\
\hline $\begin{array}{c}1-1-1 \\
3-3-3 \\
3-3-5 \\
5-5-9 \\
7-7-9 \\
9-9-9 \\
10-15-20 \\
\end{array}$ & $\begin{array}{l}0.0899 \\
0.0817 \\
0.0798 \\
0.0784 \\
0.0783 \\
0.0783 \\
0.0780 \\
\end{array}$ & $\begin{array}{l}0.1222 \\
0.1126 \\
0.1104 \\
0.1079 \\
0.1076 \\
0.1074 \\
0.1061 \\
\end{array}$ & $\begin{array}{l}0.1580 \\
0.1496 \\
0.1485 \\
0.1458 \\
0.1450 \\
0.1445 \\
0.1430 \\
\end{array}$ & $\begin{array}{l}0.1719 \\
0.1629 \\
0.1625 \\
0.1599 \\
0.1589 \\
0.1583 \\
0.1571 \\
\end{array}$ \\
\hline & \multicolumn{4}{|c|}{ (top roller) } \\
\hline $\begin{array}{c}1-1-1 \\
3-3-3 \\
3-3-5 \\
5-5-9 \\
7-7-9 \\
9-9-9 \\
10-15-20\end{array}$ & $\begin{array}{l}0.0882 \\
0.0796 \\
0.0776 \\
0.0762 \\
0.0761 \\
0.0760 \\
0.0757\end{array}$ & $\begin{array}{l}0.1212 \\
0.1112 \\
0.1089 \\
0.1064 \\
0.1062 \\
0.1060 \\
0.1047\end{array}$ & $\begin{array}{l}0.1580 \\
0.1495 \\
0.1484 \\
0.1457 \\
0.1449 \\
0.1443 \\
0.1429\end{array}$ & $\begin{array}{l}0.1704 \\
0.1593 \\
0.1589 \\
0.1562 \\
0.1551 \\
0.1545 \\
0.1532\end{array}$ \\
\hline
\end{tabular}

Table I1. Fundamental Natural Frequency for Steel Tanks with Top Free Boundary Condition, $h / R=0.001, \nu=0.3, \rho / \rho=0.127$

\begin{tabular}{||c|c|c|c|c|}
\hline \multirow{2}{*}{$\mathrm{L} / \mathrm{R}$} & \multicolumn{4}{|c|}{ Frequency Coefficient, $\mathrm{C}_{1}$} \\
\cline { 2 - 5 } & $\mathrm{H} / \mathrm{L}=1$ & $\mathrm{H} / \mathrm{L}=0.8$ & $\mathrm{H} / \mathrm{L}=0.6$ & $\mathrm{H} / \mathrm{L}=0.5$ \\
\hline 0.3 & 0.0601 & 0.0692 & 0.0829 & 0.0933 \\
0.5 & 0.0723 & 0.0838 & 0.1010 & 0.1132 \\
0.75 & 0.0823 & 0.0967 & 0.1179 & 0.1331 \\
1.0 & 0.0886 & 0.1055 & 0.1305 & 0.1483 \\
1.5 & 0.0928 & 0.1148 & 0.1465 & 0.1689 \\
2.0 & 0.0905 & 0.1161 & 0.1538 & 0.1804 \\
2.5 & 0.0856 & 0.1131 & 0.1552 & 0.1855 \\
3.0 & 0.0798 & 0.1081 & 0.1529 & 0.1858 \\
\hline
\end{tabular}


Table III. Fundamental Natural Frequency for Steel Tanks with Top Hinged Condition, $\mathrm{h} / \mathrm{R}=0.001, v=0.3, \rho_{\mathrm{d}} \rho \mathrm{\rho}=0.127$

\begin{tabular}{|l|c|c|c|c|}
\hline \multirow{2}{*}{$\mathrm{L} / \mathrm{R}$} & \multicolumn{4}{|c|}{ Frequency Coefficient, $\mathrm{C}_{1}$} \\
\cline { 2 - 5 } & $\mathrm{H} / \mathrm{L}=1$ & $\mathrm{H} / \mathrm{L}=0.8$ & $\mathrm{H} / \mathrm{L}=0.6$ & $\mathrm{H} / \mathrm{L}=0.5$ \\
\hline 0.3 & 0.0634 & 0.0718 & 0.0850 & 0.0952 \\
0.5 & 0.0783 & 0.0883 & 0.1041 & 0.1159 \\
0.75 & 0.0937 & 0.1047 & 0.1232 & 0.1373 \\
1.0 & 0.1074 & 0.1186 & 0.1388 & 0.1548 \\
1.5 & 0.1296 & 0.1412 & 0.1638 & 0.1825 \\
2.0 & 0.1445 & 0.1567 & 0.1821 & 0.2032 \\
2.5 & 0.1534 & 0.1659 & 0.1943 & 0.2181 \\
3.0 & 0.1583 & 0.1707 & 0.2013 & 0.2276 \\
\hline
\end{tabular}

Table IV. Fundamental Natural Frequency for Steel Tanks with Top Roller Condition, $\mathrm{h} / \mathrm{R}=0.001, v=0.3, \rho_{\mathrm{d}} \rho \mathrm{\rho}=0.127$

\begin{tabular}{|l|c|c|c|c||}
\hline \multirow{2}{*}{$\mathrm{L} / \mathrm{R}$} & \multicolumn{4}{|c|}{ Frequency Coefficient, $\mathrm{C}_{1}$} \\
\cline { 2 - 5 } & $\mathrm{H} / \mathrm{L}=1$ & $\mathrm{H} / \mathrm{L}=0.8$ & $\mathrm{H} / \mathrm{L}=0.6$ & $\mathrm{H} / \mathrm{L}=0.5$ \\
\hline 0.3 & 0.0613 & 0.0700 & 0.0834 & 0.0937 \\
0.5 & 0.0760 & 0.0863 & 0.1024 & 0.1143 \\
0.75 & 0.0917 & 0.1029 & 0.1216 & 0.1358 \\
1.0 & 0.1060 & 0.1174 & 0.1377 & 0.1538 \\
1.5 & 0.1294 & 0.1410 & 0.1636 & 0.1823 \\
2.0 & 0.1443 & 0.1565 & 0.1820 & 0.2032 \\
2.5 & 0.1519 & 0.1643 & 0.1930 & 0.2171 \\
3.0 & 0.1545 & 0.1666 & 0.1977 & 0.2247 \\
\hline
\end{tabular}


Table V. Frequency Coefficient, $C_{1}$, for Partially Filled Tanks with Top Free Boundary Condition (steel tanks with $\mathrm{h} / \mathrm{R}=0.001, \rho_{\mathrm{d}} \rho \rho=0.127, v=0.3$ )

\begin{tabular}{||l|c|c|c|c|c|c||}
\hline \multirow{2}{*}{$\mathrm{L} / \mathrm{R}$} & \multicolumn{2}{|c|}{$\mathrm{H} / \mathrm{L}=0.8$} & \multicolumn{2}{c|}{$\mathrm{H} / \mathrm{L}=0.6$} & \multicolumn{2}{c|}{$\mathrm{H} / \mathrm{L}=0.5$} \\
\cline { 2 - 7 } & Exact & Approx. & Exact & Approx. & Exact & Approx. \\
\hline 0.3 & 0.0692 & 0.0691 & 0.0829 & 0.0827 & 0.0933 & 0.0930 \\
0.5 & 0.0838 & 0.0835 & 0.1010 & 0.1002 & 0.1132 & 0.1123 \\
0.75 & 0.0967 & 0.0960 & 0.1179 & 0.1161 & 0.1331 & 0.1305 \\
1.0 & 0.1055 & 0.1048 & 0.1305 & 0.1280 & 0.1483 & 0.1445 \\
1.5 & 0.1148 & 0.1143 & 0.1465 & 0.1442 & 0.1689 & 0.1647 \\
2.2 & 0.1161 & 0.1159 & 0.1538 & 0.1523 & 0.1804 & 0.1772 \\
2.5 & 0.1131 & 0.1131 & 0.1552 & 0.1547 & 0.1855 & 0.1837 \\
3.0 & 0.1081 & 0.1083 & 0.1529 & 0.1532 & 0.1858 & 0.1856 \\
\hline
\end{tabular}

Table VI. Frequency Coefficient, $\mathrm{C}_{1}$, for Partially Filled Tanks with Top Hinged Boundary Conditions (steel tanks with $h / R=0.001, \rho_{/} \rho=0.127, v=0.3$ )

\begin{tabular}{|l|c|c|c|c|c|c||}
\hline \multirow{2}{*}{$\mathrm{L} / \mathrm{R}$} & \multicolumn{2}{|c|}{$\mathrm{H} / \mathrm{L}=0.8$} & \multicolumn{2}{c|}{$\mathrm{H} / \mathrm{L}=0.6$} & \multicolumn{2}{c|}{$\mathrm{H} / \mathrm{L}=0.5$} \\
\cline { 2 - 7 } & Exact & Approx. & Exact & Approx. & Exact & Approx. \\
\hline 0.3 & 0.0718 & 0.0724 & 0.0850 & 0.0862 & 0.0952 & 0.0966 \\
0.5 & 0.0883 & 0.0891 & 0.1041 & 0.1056 & 0.1159 & 0.1178 \\
0.75 & 0.1047 & 0.1059 & 0.1232 & 0.1248 & 0.1373 & 0.1388 \\
1.0 & 0.1186 & 0.1207 & 0.1388 & 0.1411 & 0.1548 & 0.1565 \\
1.5 & 0.1412 & 0.1464 & 0.1638 & 0.1701 & 0.1825 & 0.1874 \\
2.0 & 0.1567 & 0.1664 & 0.1821 & 0.1952 & 0.2032 & 0.2147 \\
2.5 & 0.1659 & 0.1806 & 0.1943 & 0.2160 & 0.2181 & 0.2388 \\
3.0 & 0.1707 & 0.1900 & 0.2013 & 0.2323 & 0.2276 & 0.2592 \\
\hline
\end{tabular}


Table VII. Frequency Coefficient, $C_{1}$, for Partially Filled Tanks with Top Roller Boundary Conditions (steel tanks with $h / R=0.001, \rho_{\downarrow} / \rho=0.127, v=0.3$ )

\begin{tabular}{|l|c|c|c|c|c|c||}
\hline \multirow{2}{*}{$\mathrm{L} / \mathrm{R}$} & \multicolumn{2}{|c|}{$\mathrm{H} / \mathrm{L}=0.8$} & \multicolumn{2}{c|}{$\mathrm{H} / \mathrm{L}=0.6$} & \multicolumn{2}{c|}{$\mathrm{H} / \mathrm{L}=0.5$} \\
\cline { 2 - 7 } & Exact & Approx. & Exact & Approx. & Exact & Approx. \\
\hline 0.3 & 0.0700 & 0.0700 & 0.0834 & 0.0834 & 0.0937 & 0.0935 \\
0.5 & 0.0863 & 0.0864 & 0.1024 & 0.1022 & 0.1143 & 0.1139 \\
0.75 & 0.1029 & 0.1031 & 0.1216 & 0.1211 & 0.1358 & 0.1345 \\
1.0 & 0.1174 & 0.1183 & 0.1377 & 0.1375 & 0.1538 & 0.1521 \\
1.5 & 0.1410 & 0.1453 & 0.1636 & 0.1674 & 0.1823 & 0.1834 \\
2.0 & 0.1565 & 0.1632 & 0.1820 & 0.1938 & 0.2032 & 0.2119 \\
2.5 & 0.1643 & 0.1804 & 0.1930 & 0.2156 & 0.2171 & 0.2373 \\
3.0 & 0.1666 & 0.1886 & 0.1977 & 0.2323 & 0.2247 & 0.2587 \\
\hline
\end{tabular}

Table VIII. Frequency Coefficient, $C_{1}$, for Partially Filled Tanks with Top Free Boundary Condition (concrete tanks with $h / R=0.01, \rho / \rho=0.4, v=0.15$ )

\begin{tabular}{|l|c|c|c|c|c|c||}
\hline \multirow{2}{*}{$\mathrm{L} / \mathrm{R}$} & \multicolumn{2}{|c|}{$\mathrm{H} / \mathrm{L}=0.8$} & \multicolumn{2}{c|}{$\mathrm{H} / \mathrm{L}=0.6$} & \multicolumn{2}{c|}{$\mathrm{H} / \mathrm{L}=0.5$} \\
\cline { 2 - 7 } & Exact & Approx. & Exact & Approx. & Exact & Approx. \\
\hline 0.3 & 0.1504 & 0.1469 & 0.2012 & 0.1808 & 0.2413 & 0.2052 \\
0.5 & 0.1623 & 0.1619 & 0.2061 & 0.2038 & 0.2434 & 0.2368 \\
0.75 & 0.1796 & 0.1795 & 0.2225 & 0.2222 & 0.2564 & 0.2553 \\
1.0 & 0.1932 & 0.1934 & 0.2393 & 0.2393 & 0.2739 & 0.2738 \\
1.5 & 0.2087 & 0.2095 & 0.2637 & 0.2650 & 0.3030 & 0.3044 \\
2.0 & 0.2109 & 0.2128 & 0.2755 & 0.2793 & 0.3204 & 0.3252 \\
2.5 & 0.2048 & 0.2076 & 0.2764 & 0.2838 & 0.3261 & 0.3368 \\
3.0 & 0.1947 & 0.1981 & 0.2700 & 0.2812 & 0.3228 & 0.3406 \\
\hline
\end{tabular}


Table IX. Frequency Coefficient, $C_{1}$, for Partially Filled Tanks with Top Hinged Boundary Conditions (concrete tanks with $h / R=0.01, \rho_{/} \rho=0.4, v=0.15$ )

\begin{tabular}{|l|c|c|c|c|c|c||}
\hline \multirow{2}{*}{$\mathrm{L} / \mathrm{R}$} & \multicolumn{2}{|c|}{$\mathrm{H} / \mathrm{L}=0.8$} & \multicolumn{2}{c|}{$\mathrm{H} / \mathrm{L}=0.6$} & \multicolumn{2}{c||}{$\mathrm{H} / \mathrm{L}=0.5$} \\
\cline { 2 - 7 } & Exact & Approx. & Exact & Approx. & Exact & Approx. \\
\hline 0.3 & 0.1537 & 0.1612 & 0.2049 & 0.2459 & 0.2459 & 0.3452 \\
0.5 & 0.1684 & 0.1689 & 0.2105 & 0.2125 & 0.2474 & 0.2559 \\
0.75 & 0.1908 & 0.1930 & 0.2300 & 0.2332 & 0.2625 & 0.2656 \\
1.0 & 0.2123 & 0.2162 & 0.2515 & 0.2573 & 0.2835 & 0.2895 \\
1.5 & 0.2501 & 0.2590 & 0.2906 & 0.3032 & 0.3243 & 0.3368 \\
2.0 & 0.2784 & 0.2946 & 0.3225 & 0.3453 & 0.3591 & 0.3813 \\
2.5 & 0.2965 & 0.3215 & 0.3452 & 0.3820 & 0.3860 & 0.4223 \\
3.0 & 0.3065 & 0.3402 & 0.3590 & 0.4122 & 0.4041 & 0.4585 \\
\hline
\end{tabular}

Table X. Frequency Coefficient, $C_{1}$, for Partially Filled Tanks with Top Roller Boundary Conditions (concrete tanks with $\mathrm{h} / \mathrm{R}=0.01, \rho / \rho=0.5, v=0.15$ )

\begin{tabular}{|l|c|c|c|c|c|c||}
\hline \multirow{2}{*}{$\mathrm{L} / \mathrm{R}$} & \multicolumn{2}{|c|}{$\mathrm{H} / \mathrm{L}=0.8$} & \multicolumn{2}{c|}{$\mathrm{H} / \mathrm{L}=0.6$} & \multicolumn{2}{c||}{$\mathrm{H} / \mathrm{L}=0.5$} \\
\cline { 2 - 7 } & Exact & Approx. & Exact & Approx. & Exact & Approx. \\
\hline 0.3 & 0.1528 & 0.1603 & 0.2039 & 0.2452 & 0.2447 & 0.3446 \\
0.5 & 0.1676 & 0.1679 & 0.2098 & 0.2112 & 0.2467 & 0.2546 \\
0.75 & 0.1904 & 0.1922 & 0.2296 & 0.2318 & 0.2621 & 0.2640 \\
1.0 & 0.2122 & 0.2157 & 0.2514 & 0.2562 & 0.2834 & 0.2880 \\
1.5 & 0.2498 & 0.2590 & 0.2905 & 0.3028 & 0.3242 & 0.3358 \\
2.0 & 0.2762 & 0.2941 & 0.3208 & 0.3453 & 0.3579 & 0.3810 \\
2.5 & 0.2904 & 0.3187 & 0.3401 & 0.3817 & 0.3819 & 0.4225 \\
3.0 & 0.2955 & 0.3336 & 0.3494 & 0.4103 & 0.3958 & 0.4580 \\
\hline
\end{tabular}


20

Table XI. Natural Frequencies of Partially Filled Tanks in the Numerical Example, in cps

\begin{tabular}{|c|r|r|r|r|r|r|r|r||}
\hline \multirow{4}{*}{} & \multicolumn{4}{|c|}{ Broad Tank } & \multicolumn{4}{c|}{ Tall Tank } \\
\cline { 2 - 9 } & \multicolumn{2}{|c|}{ First Mode } & \multicolumn{2}{c|}{ Second Mode } & \multicolumn{2}{|c|}{ First Mode } & \multicolumn{2}{c|}{ Second Mode } \\
\cline { 2 - 9 } & Present & Ref. 7 & Present & Ref. 7 & Present & Ref. 7 & Present & Ref. 7 \\
\hline 1.0 & 6.27 & 6.18 & 11.36 & 11.28 & 5.39 & 5.31 & 15.96 & 15.64 \\
0.8 & 7.33 & 7.24 & 13.02 & 12.96 & 7.19 & 7.05 & 19.08 & 18.76 \\
0.6 & 8.90 & 8.79 & 15.42 & 15.37 & 9.90 & 9.64 & 22.83 & 22.45 \\
0.5 & 10.02 & 9.88 & 17.25 & 17.05 & 11.79 & 11.42 & 24.56 & 24.03 \\
0.3 & 13.94 & 13.82 & 24.33 & 24.00 & 16.97 & 16.46 & 26.03 & 25.61 \\
0.0 & 34.35 & 34.04 & 43.94 & 43.86 & 19.39 & 19.26 & 57.01 & 56.42 \\
\hline
\end{tabular}



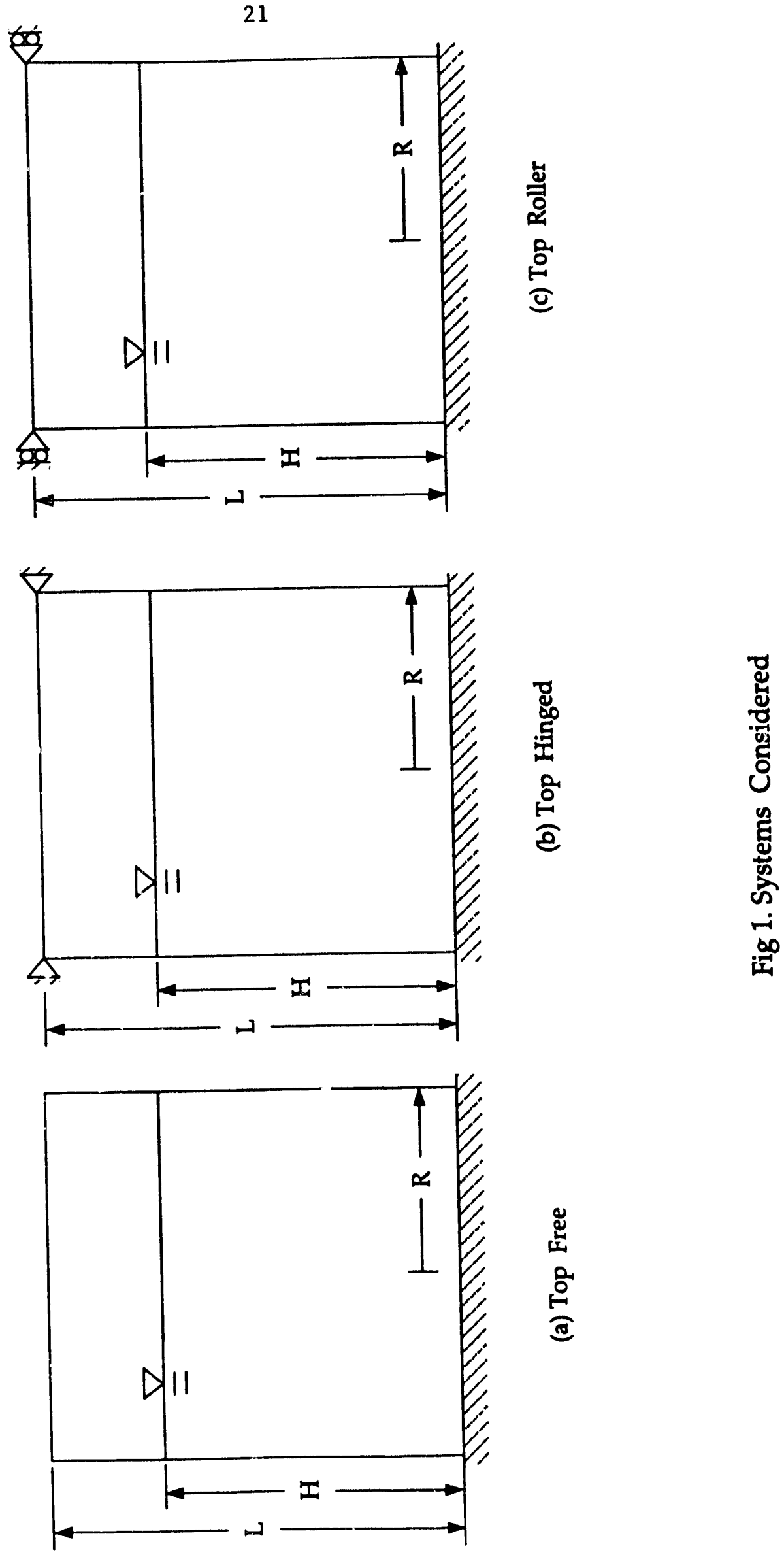

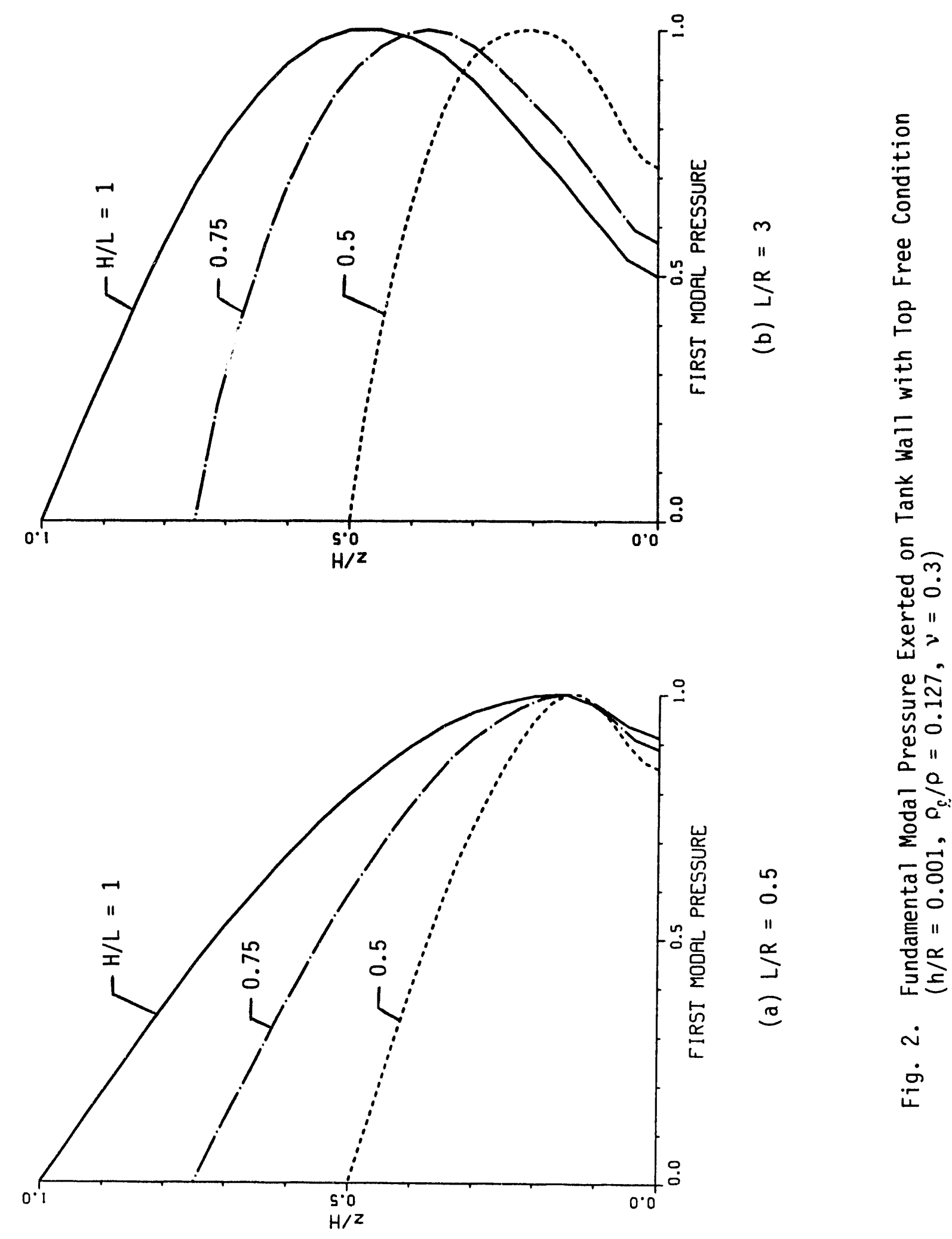

崩

\&

ฉั "

웅

$\frac{\pi}{2} a^{\circ}$

бо

둥

売"

䒿足

$\dot{\sim}$

$\dot{\pi}$ 


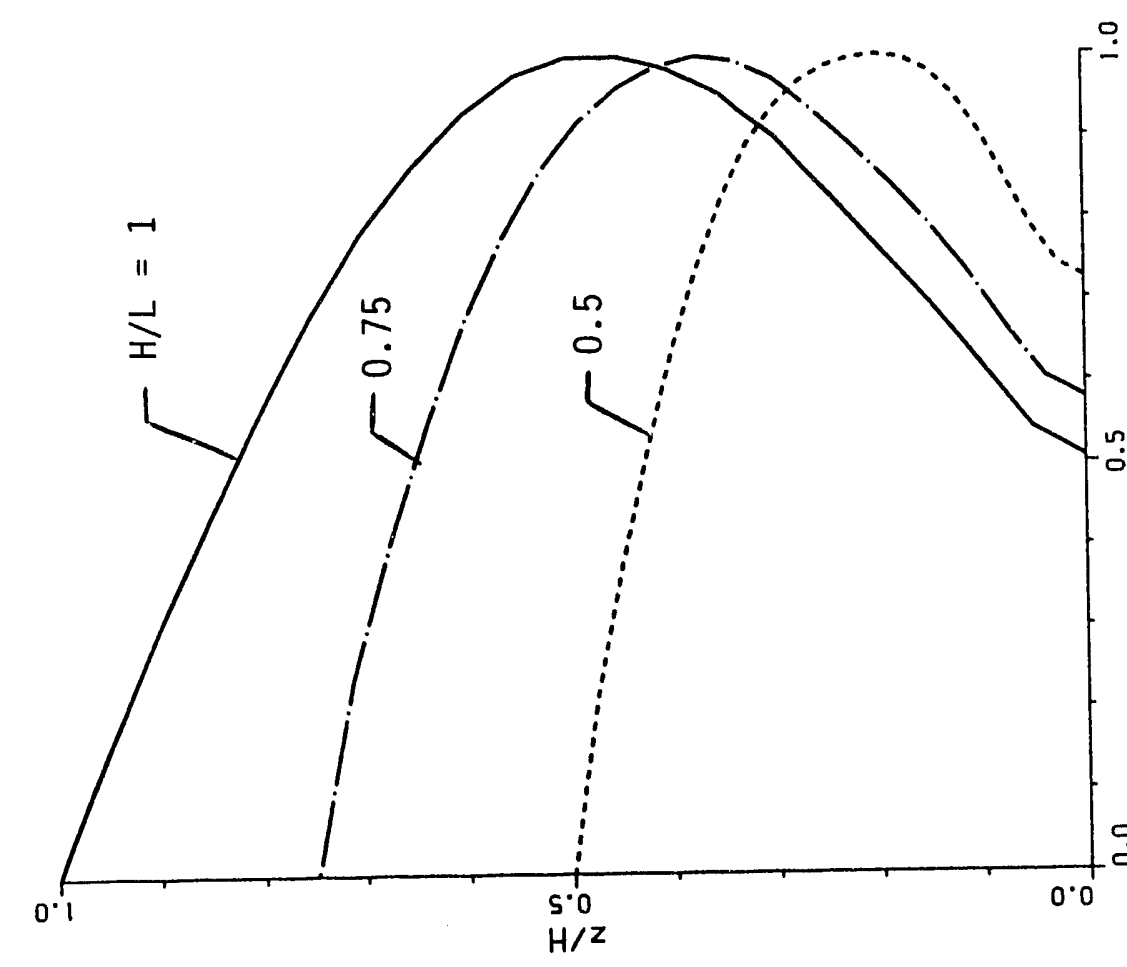

5
$\frac{1}{0}$
$\frac{0}{0}$
0
0

崖 导

宸 m

홍 응

点

$\frac{5}{\frac{1}{3}}$

$\frac{\pi}{3}$

苑

$\frac{\mathscr{C}}{\square}$

ธิ

\%

$+\frac{}{4}$

के

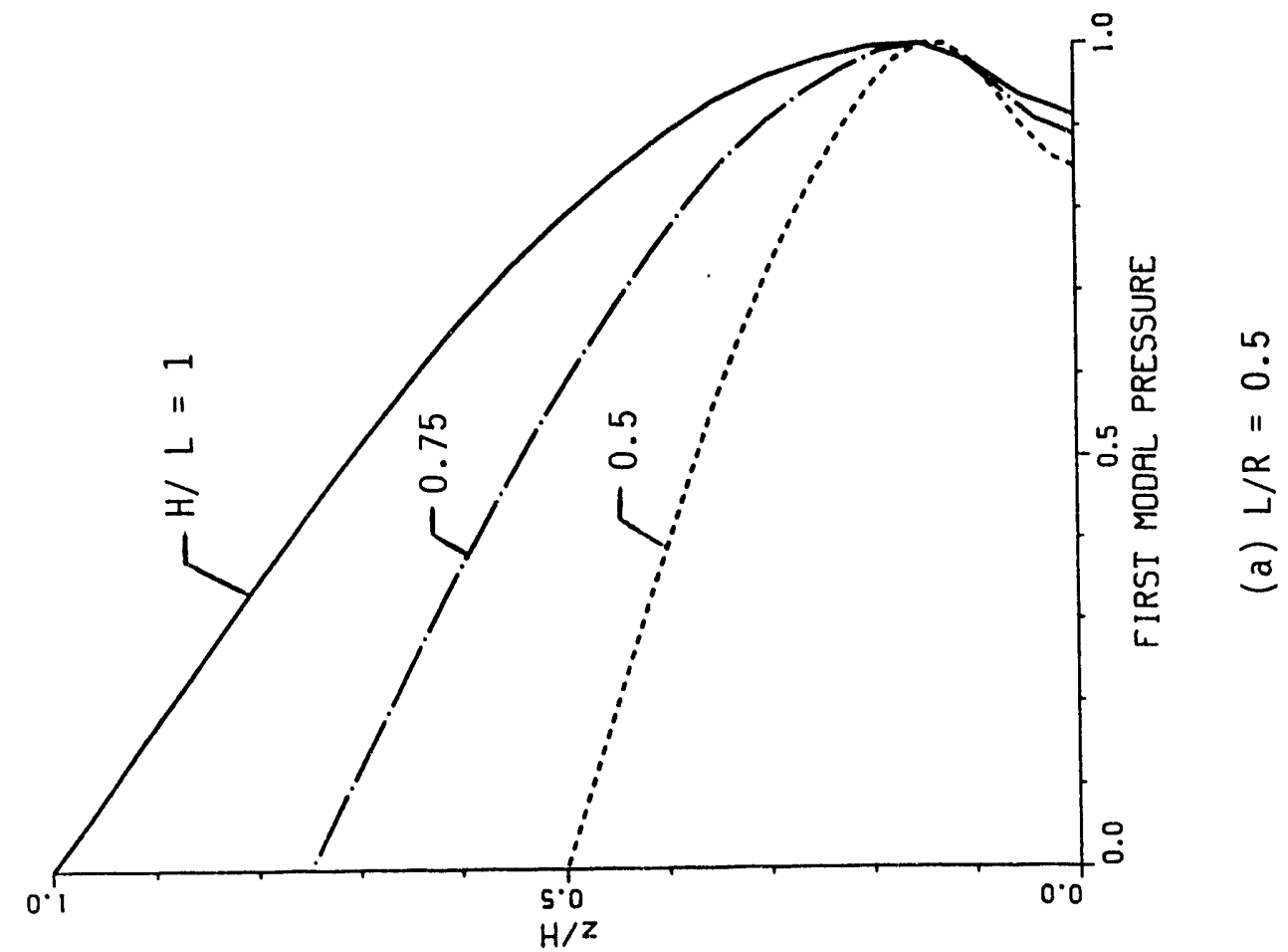

هิ

ปั

ज。

¿ั"

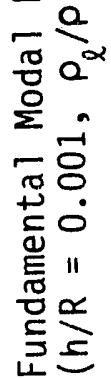

$\dot{m}$

$\dot{\pi}$ 

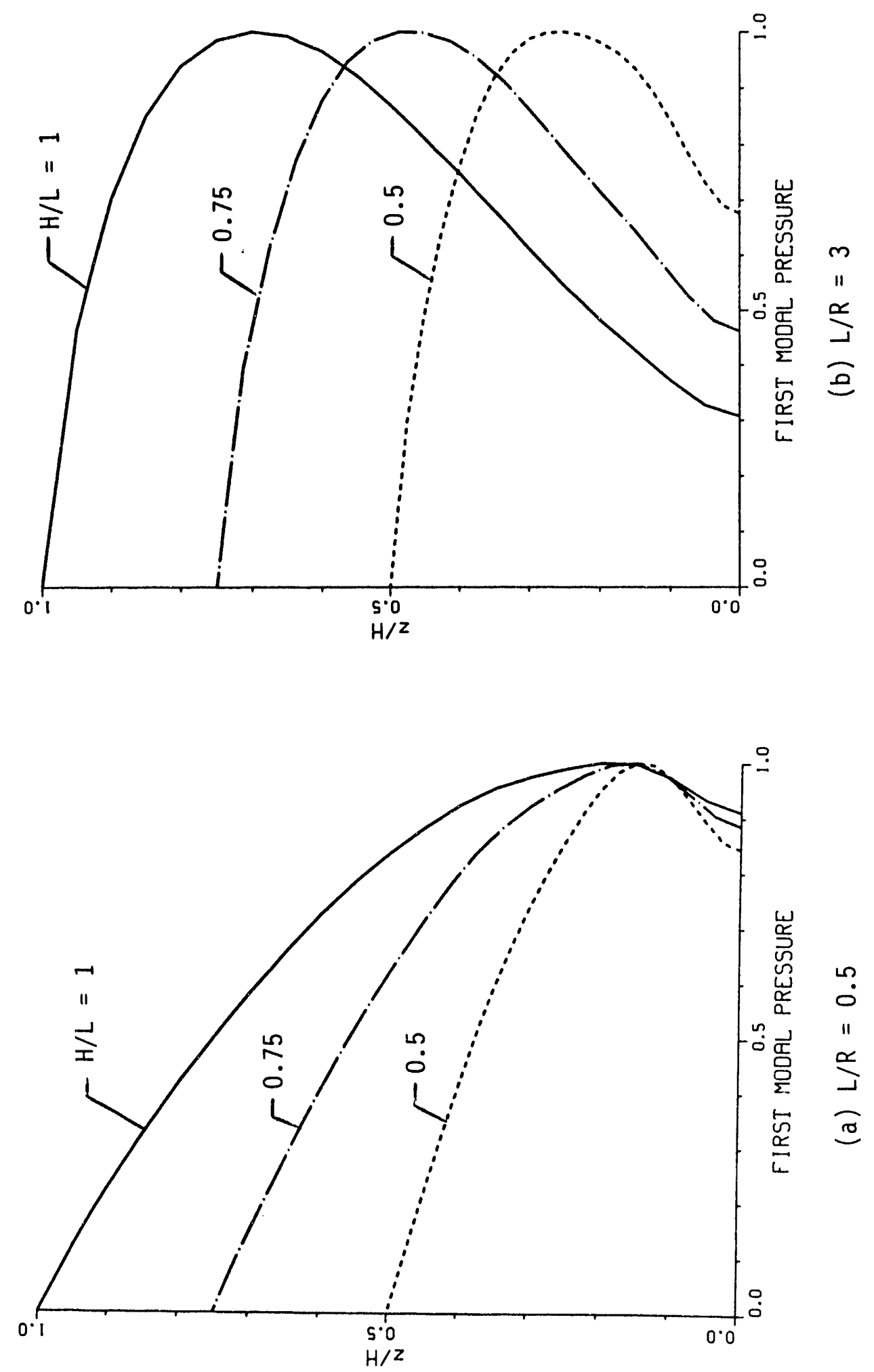

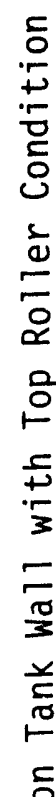

m

$+$

高>

究

ญั

ฉ

To

응

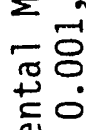

嵌 1

용

吉至

$\dot{\sigma}$

它 

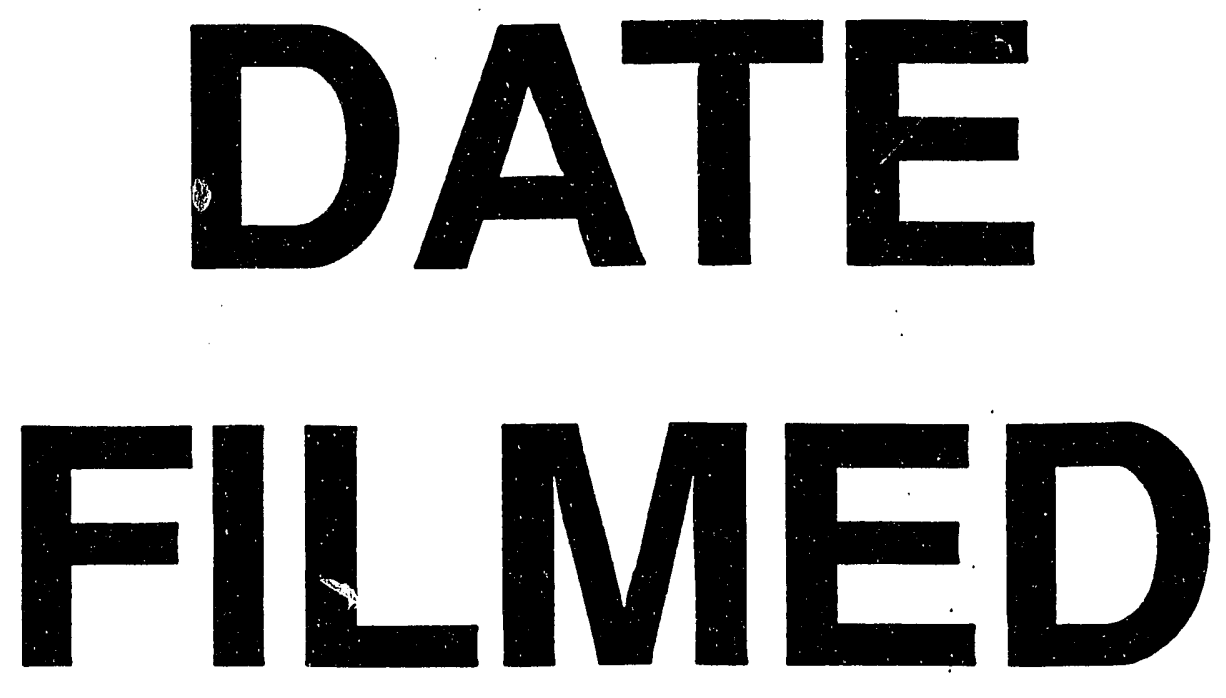

$10 / 13 / 93$
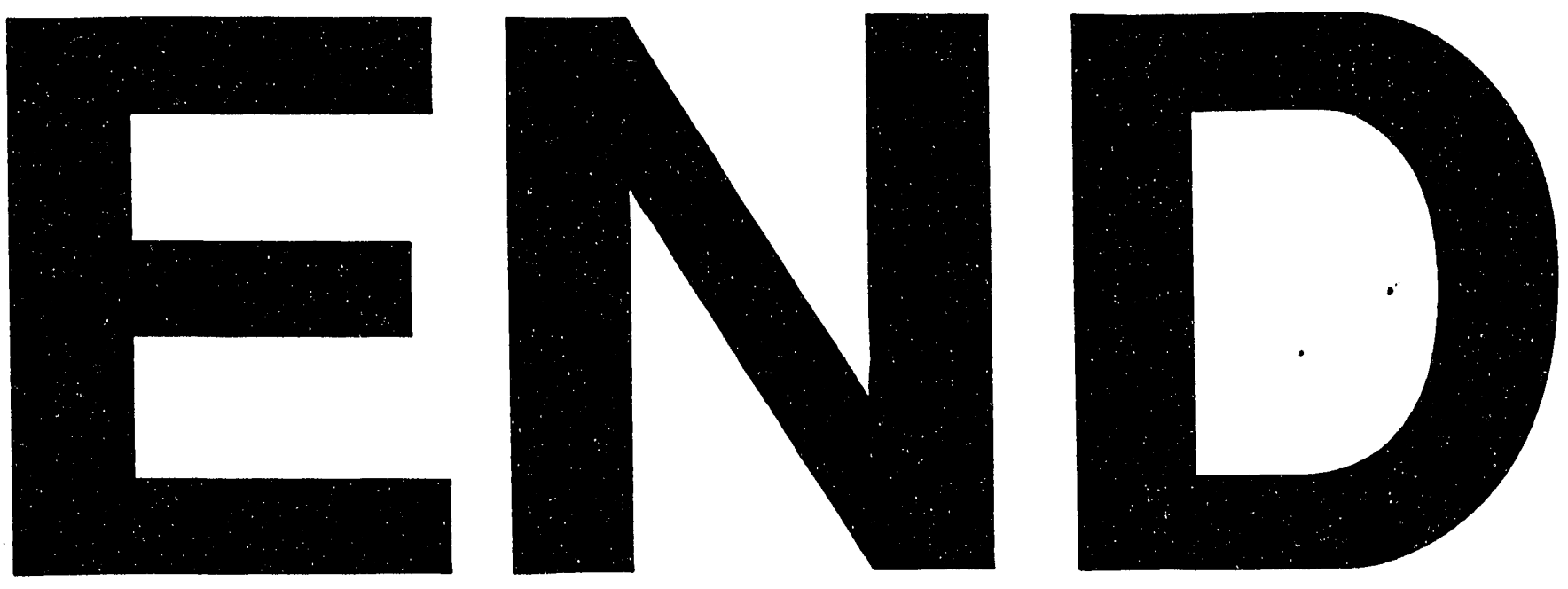
